\title{
Role for MicroRNAs in Regulating Glucocorticoid Response and Resistance in Multiple Myeloma
}

\author{
Michael A. Tessel • Ashley L. Benham • \\ Nancy L. Krett • Steven T. Rosen • \\ Preethi H. Gunaratne
}

Published online: 5 April 2011

(C) Springer Science+Business Media, LLC 2011

\begin{abstract}
Glucocorticoids (GCs) are widely used in the treatment of hematological malignancies such as multiple myeloma. However, the development of resistance to GCs limits their clinical utility. Response to GCs is dependent on an active glucocorticoid receptor, GR- $\alpha$, expressed at wildtype levels in the GC-sensitive cell line (MM.1S). GCresistant derivative cell lines MM.1Re and MM.1RL display significant downregulation of GR- $\alpha$ transcripts. In this study, we report that a luciferase reporter containing the $3^{\prime}-$ UTR of GR- $\alpha$ is significantly repressed in MM.1R cells when compared to MM.1S cells, suggesting that one or several microRNAs that are upregulated in MM.1R maybe in part responsible for the downregulation of the GR- $\alpha$ transcript. To examine posttranscriptional mechanisms of GR regulation, we examined miRNAs that have complimentary binding sites in the $3^{\prime}$-UTR of GR- $\alpha$
\end{abstract}

Preethi H. Gunaratne and Steven T. Rosen contributed equally to this work.

Electronic supplementary material The online version of this article (doi:10.1007/s12672-011-0072-8) contains supplementary material, which is available to authorized users.

M. A. Tessel $\cdot$ N. L. Krett $(\bowtie) \cdot S$. T. Rosen

Robert H. Lurie Comprehensive Cancer Center,

Northwestern University,

Chicago, IL 60611, USA

e-mail: n-krett@northwestern.edu

A. L. Benham • P. H. Gunaratne

Department of Biology and Biochemistry, University of Houston, Houston, TX 77204, USA

\section{P. H. Gunaratne}

Department of Pathology, Baylor College of Medicine,

Houston, TX 77030, USA and found miR-130b, miR-181a, and miR-636 to be differentially expressed between GC-sensitive and GCresistant MM.1 cell lines. Overexpression of miR-130b in MM.1S cells results in decreased expression of endogenous GR protein and decreased activity of the luciferase reporter. In addition, in MM.1S cells, the downstream GC response of glucocorticoid-induced leucine zipper induction is decreased by the overexpression of miR-130b, and further miR-130b inhibits GC-induced apoptosis and causes resistance to GCs.

Keywords Multiple myeloma $\cdot$ MicroRNA . Glucocorticoids · Glucocorticoid receptor · Glucocorticoid resistance

\section{Introduction}

Multiple myeloma (MM) is a malignancy of plasma cells and is characterized by an increase in expression of monoclonal immunoglobulin. Although new therapies have increased survival, MM remains an incurable disease. Glucocorticoids (GC) are the most effective first-line therapy in the treatment of MM. For this reason, GCs are most commonly used in combination with either classical chemotherapy or with novel therapeutics. However, development of resistance to GCs limits the clinical utility of this drug. The exact mechanism of $\mathrm{GC}$ resistance in MM remains unknown; however, previous studies in a variety of hematologic malignancies have shown that expression of the glucocorticoid receptor (GR) is required for GC response. Therefore, GR and its regulation are crucial determinants of the efficacy of GC treatment [1-5]. 
GR is a member of the nuclear hormone receptor superfamily. It acts as a ligand-activated transcription factor and is involved in altering gene expression in a spectrum of signaling pathways. Decreased expression of the receptor has been consistently associated with decreased response to GC therapy, and restoration of GR in receptor-negative MM cell lines leads to partial restoration of GC response, emphasizing that GR expression is directly linked to GC response [5]. Reduced GR expression and or mutation of GR is also involved in GC resistance in other models [6-8]. In MM patients, decreased levels of GR have recently been linked to poor disease prognosis [9].

Our lab has previously established cell lines from the peripheral blood of an MM patient who had been treated with GCs and became resistant to this treatment. Three distinct cell lines were derived from the parental cell line (MM.1), one which is highly sensitive to glucocorticoids (MM.1S) and two that are completely resistant to glucocorticoid-induced cell death (MM.1Re, MM.1RL). Compared to wild-type expression of GR, as observed in MM.1S, GR expression is reduced in MM.1Re and absent in MM.1RL [10]. This cell line is ideal for the study of glucocorticoid resistance in MM since the cells share a common genetic background and differ only in their sensitivity to GCs. The molecular basis for differential GR expression in these cell lines is not completely understood. Treatment of MM cell lines with a demethylating agent did not restore GR expression, indicating that promoter methylation is not responsible for the reduction in GR expression. Transcription of GR is initiated in all cell lines at approximately equivalent levels; however, the full-length transcript is expressed at much lower levels in MM.1Re and MM.1RL cells [4]. Collectively, these observations indicate that downregulation of the GR transcript is likely to be mediated through posttranscriptional mechanisms. The same study suggests that there may be a block in transcriptional elongation, but this mechanism is still undefined [4].

One common mechanism for posttranscriptional gene regulation is through microRNAs. MicoRNAs (miRNAs) are $\sim 22$-nucleotide noncoding RNAs that negatively regulate target genes by binding predominantly to the 3'UTR of target mRNA transcripts. Approximately $60 \%$ of the human genome is regulated by at least one miRNA, and each miRNA can target hundreds of genes [11, 12]. miRNAs have been documented as regulating vital growth-related genes in many cancers, and miRNA dysregulation has been documented in multiple myeloma [13-15]. The regulation of GR by miRNAs in MM has not yet been reported. Here, we report that miRNAs are involved in the regulation of GR expression in the context of GC response and resistance. We further identify miR-130b as one miRNA that may play a role in the downregulation of GR in GC-resistant cells.

\section{Materials and Methods}

Cell Culture All cell culture medium, serum, and antibiotics were purchased from GIBCO/Invitrogen (Carlsbad, CA). The MM.1S, MM.1Re, and MM.1RL cell lines were developed previously in our laboratory. The MM.1S, MM.1Re, MM.1RL cells were grown in RPMI-1640 supplemented with $10 \%$ fetal bovine serum, $2 \mathrm{mmol} / \mathrm{L}$ glutamine, $100 \mathrm{U} / \mathrm{mL}$ penicillin, $100 \mathrm{~g} / \mathrm{mL}$ streptomycin, $2.5 \mathrm{~g} / \mathrm{mL}$ fungizone, and $5 \mathrm{~g} / \mathrm{mL}$ plasmocin (InvivoGen, San Diego, CA) in a $37^{\circ} \mathrm{C}$ incubator with $5 \% \mathrm{CO}_{2}$.

Chemicals Dexamethasone (Sigma) dissolved in 100\% ethanol at a stock concentration of $2.5 \mathrm{mM}$ was added to cell culture media containing cells and incubated for either 24 or $48 \mathrm{~h}$ (as specified).

Immunoblots Immunoblots were performed as described previously with these modifications [2]. Following treatment, $5 \times 10^{6}$ cells were harvested and washed with $1 \times$ phosphate-buffered saline (PBS) and lysed with $25 \mathrm{uL}$ of Complete Lysis M (Roche) as described in the product manual. Twenty-five micrograms of protein lysate was separated on $8-16 \%$ gel and subsequently transferred to a polyvinylidene chloride membrane (Millipore) as described. Membranes were blocked in BLOK Casein in TBS (G Biosciences), which was also used for antibody incubation. The antibodies used were glucocorticoid receptor (Santa Cruz H300), poly(ADP-ribose) polymerase (Cell Signaling), and GAPDH (Chemicon).

$q P C R$ Total RNA from the cell lines was extracted using MirVana (Ambion) to maximize isolation of small RNA pools. For miRNA measurement, Taqman MicroRNA Assay Kit specific to miR-130b and RNU6B as a control (Applied Biosystems) is used for RT reaction and amplification. For measurement of GR- $\alpha$ and glucocorticoidinduced leucine zipper (GILZ), Taqman Gene Expression Assays were used as described previously [2].

Prediction of miRNA-GR Functional Interactions miRNAs predicted to target differentially expressed GR were identified using TargetScanHuman (release 5.0; http:// www.targetscan.org/), PicTar (http://pictar.mdc-berlin.de/), and miRanda (http://www.microrna.org/) [16].

Plasmid Construction Using primers for the end of exon 9 of GR (5'-GAAGGAAACTCCAGCCAG-3') and the beginning of the pCD sequence from the vector (5'-GCATCCTAGTTGTTTGTCC-3'), the 3'UTR of GR was amplified from OB7 [17] by PCR after vector linearization by Nde1. pMIR-REPORT [18] plasmid was obtained from Clontech, and standard molecular biology approaches were used to 
clone the amplified GR 3'UTR downstream of the luciferase gene.

Luciferase Assay One nanomole pMIR-REPORT or pMIRREPORT-GR3'UTR was cotransfected with Renilla Luciferase into MM cells using Amaxa Nucleofector 1 and Nucleofector Kit V (Program O23). Forty-eight hours after transfection, the cells were harvested and lysed using buffer from Promega Dual Luciferase Reporter Kit following manufacturer's protocol. A Turner Designs 20/20 model luminometer was used to measure the luciferase activity, and the ratio between firefly luciferase and renilla was recorded. This transfection was performed concurrently with miRNA mimics as indicated.

miRNA Mimic Transfections Mimics purchased from Dharmacon were transfected into cells using Amaxa Nucleofector 1 and Nucleofector Kit V, program O23 at varying concentrations. As a negative control, we purchased miRNA mimic negative controls which contain a nonspecific RNA sequence (Dharmacon).

Cell Proliferation Assay Promega CellTiter 96 Aqueous Nonradioactive Cell Proliferation Assay was used. Cells were plated in 96-well plates at 25,000 cells per well and $490 \mathrm{~nm}$ absorbance measured as proportional to number of live cells as previously described [19, 20].

AnnexinV Staining Subsequent to specific treatments, cells were washed in PBS and stained with AnnexinVfluorescein isothiocyanate/APC according to the manufacturer's instructions. Samples were run on Dako CyAnTM ADP analyzer. Data analysis was performed with the FCS Express version 3 (De Novo Software, Los Angeles, CA).

A.

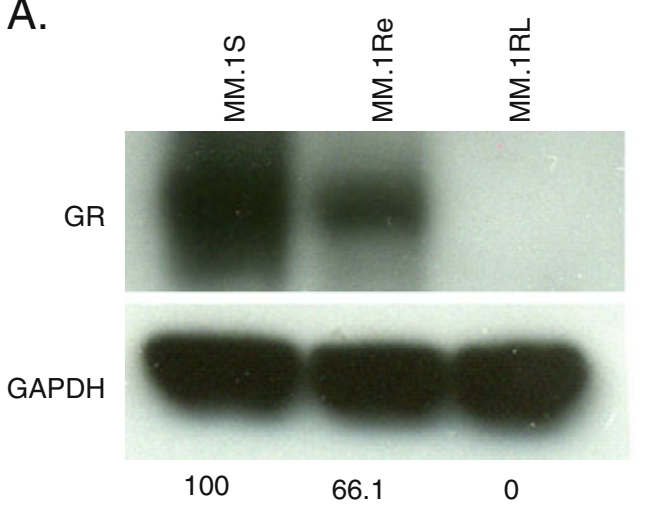

B.

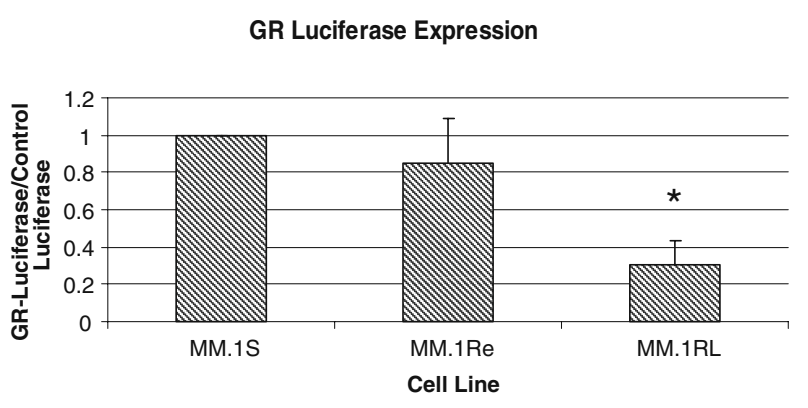

Fig. 1 Relative expression of GR protein in MM.1 cell lines. a A representative immunoblot for GR in untreated MM.1S, MM.1Re, and MM.1RL. Quantification by densitometry is indicated below each lane and normalized to expression levels in MM.1S cells. b Luciferase expression is decreased in GC-resistant cells. Using a GR $3^{\prime} \mathrm{UTR}$

\section{Results}

The 3'UTR of GR- $\alpha$ Is Targeted for Repression in GC-Resistant MM.1R Cell Lines

In agreement with previous data, we have observed that between the subclones of the MM.1 cell line, there is differential expression of glucocorticoid receptor mRNA and protein. The glucocorticoid-sensitive cell line MM.1S expresses high levels of GR, while in the GC-resistant cell lines MM.1Re and MM.1RL, GR expression is greatly reduced (Fig. 1a) [10]. Previous data show that GR promoter usage is not altered between these cell lines [21], and promoter methylation is not involved [4]. One mechanism of posttranscriptional regulation is through differential expression of miRNAs. In order to assess a potential role for miRNAs in the decreased expression of GR, we cloned the 3 '-UTR of GR into a luciferase reporter. The reporter construct was transfected into MM.1S, MM.1Re, and MM.1RL cells, and luciferase activity was measured after $48 \mathrm{~h}$. We observed a significant reduction in luciferase activity in the GC-resistant cell lines as compared to MM.1S (Fig. 1b). These results strongly suggest that miRNAs may be involved in the regulation of GR in the context of GC resistance in MM.

Identification of MiRNA Candidates

That May Be Responsible for Repressing GR- $\alpha$

in GC-Resistant MM.1R Using Luciferase Reporter Screens

Using TargetScan 4.1 and 5.1 [22, 23], we identified a set of miRNAs that are predicted to target GR. Through bioinformatics, miRNAs miR-130b, miR-181a, and miR636 were selected as potential candidates that may be responsible for the posttranscriptional silencing of GR in reporter construct, luciferase activity is measured $48 \mathrm{~h}$ after transfection as described in the "Materials and Methods" Section. Activity is normalized to the relative light units measured in the MM.1S cells (relative to MM.1S, $* p<0.01$ ) 
GC-resistant cells based on seed sequences present in the GR- $\alpha 3^{\prime}$ UTR (Fig. 2a). We then used a luciferase reporter containing the $3^{\prime}$-UTR of GR to screen the impact of these miRNAs on the GR transcript by cotransfecting the luciferase reporter with miRNA mimics into MM.1S cells and assaying for luciferase activity. From the results shown in Fig. 3c, we identified miR-130b to consistently cause a reduction in luciferase activity when compared to the control mimic sequences. While this reduction is not statistically significant $(p=0.11)$ due to high variability in luciferase experiments, miR-130b was the only miRNA that caused a downward trend in GR 3'UTR luciferase expression.

Taqman real-time PCR was used to compare the expression patterns of miR-130b in GC-sensitive (MM.1S) and GC-resistant MM cell lines (MM.1R). MicroRNA$130 \mathrm{~b}$ expression was consistently observed to be significantly increased in MM.1R compared to MM.1S (Fig. 2b). To determine if miR-130b is able to functionally repress GR, we introduced increasing concentrations of miR-130b mimic into MM.1S and measured the expression of GR protein. Increased miR-130b expression was confirmed by
qRT-PCR (Fig. S1). These studies demonstrate that the introduction of the miR-130b mimic caused a significant decrease in GR expression at the protein level measured $48 \mathrm{~h}$ after transfection (Fig. 3a). In a concentrationdependent manner, miR-130b mimic decreased the activity of the GR 3'UTR luciferase reporter construct (Fig. 3b). Collectively, these results suggest that GR- $\alpha$ is a direct target of miR-130b.

Overexpression of miR-130b in MM.1S Decreases GC-Stimulated Responses

To determine whether the introduction of miR-130b impacts GC sensitivity, miRNA-130b mimic or control miRNA was transfected into MM.1S cells. After $24 \mathrm{~h}$, the transfected cells were either treated with a range of Dex concentrations or vehicle control for $48 \mathrm{~h}$. We measured the impact of miR-130b on the GC regulation of cell viability using the MTS assay described in "Materials and Methods" Section. As shown in Fig. 4a, we observe a decrease in GC sensitivity compared to controls as measured by increased cell viability. In parallel transfections in MM.1S, we treated

A.

\begin{tabular}{|c|c|c|c|}
\hline & & $\begin{array}{l}\text { redicted consequential pairing of target region } \\
\text { (top) and miRNA (bottom) }\end{array}$ & $\begin{array}{l}\text { seed } \\
\text { match }\end{array}$ \\
\hline $\begin{array}{l}\text { Position } 1964-1970 \text { of NR3C1 } 3 \text { ' UTR } \\
\text { hsa-miR-130b }\end{array}$ & & 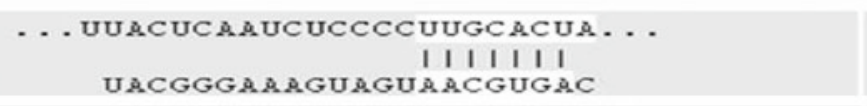 & 8mer \\
\hline $\begin{array}{l}\text { Position } 2253-2259 \text { of NR3C1 } 3 \text { ' UTR } \\
\text { hsa-miR-181a }\end{array}$ & $\begin{array}{l}5 \\
3\end{array}$ & 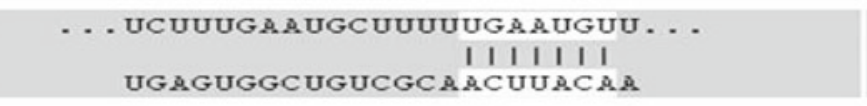 & $7 \mathrm{me}$ \\
\hline $\begin{array}{l}\text { Position } 2338-2344 \text { of NR3C1 3. UTR } \\
\text { hsa-miR-181a }\end{array}$ & 5. & 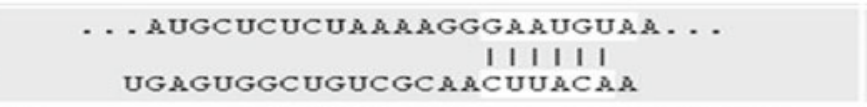 & 7 mer-1A \\
\hline $\begin{array}{l}\text { Position } 2501-2507 \text { of NR3C1 } 3^{\circ} \mathrm{U} \\
\text { hsa-miR-636 }\end{array}$ & ITR & $\begin{array}{l}\text {.. GUGGUUAAAACCAGAAAGCACAU... } \\
\text { GACGCCCGCCCUGCUCGUUCGUGU }\end{array}$ & $7 \mathrm{~ms}$ \\
\hline
\end{tabular}

B.

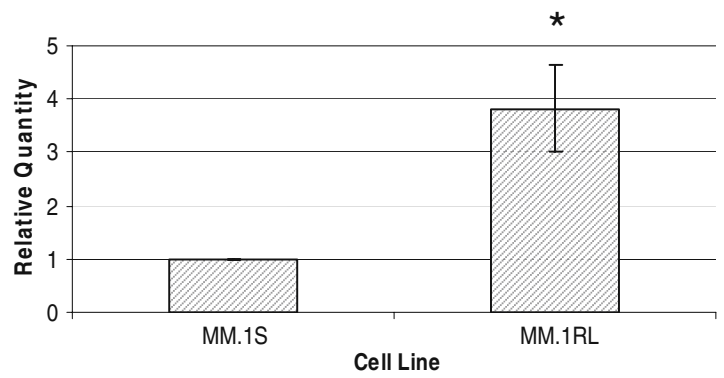

Fig. 2 Identification of GR-specific miRNA. a MicroRNAs predicted to target GR- $\alpha$. Diagram of potential seed sequence matches within the GR 3'UTR using Targetscan program. b Relative expression of endogenous miR-130b is accomplished by qRT-PCR analysis in MM.1RL cells relative to the expression in MM.1S cells $\left({ }^{*} p<0.05\right)$.
C.

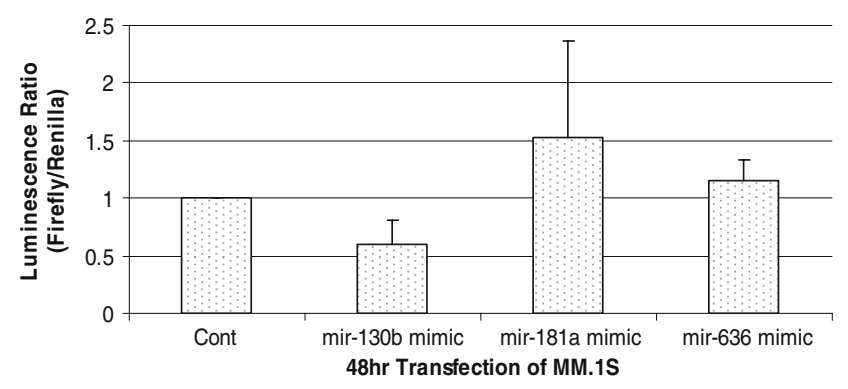

c Screening predicted miRNAs using GR- $\alpha-3^{\prime}$-UTR luciferase reporter assay. Luciferase activity was measured $48 \mathrm{~h}$ after transfection, and miRNA mimic expression is compared to cells transfected with the negative control miRNA mimic 
A.

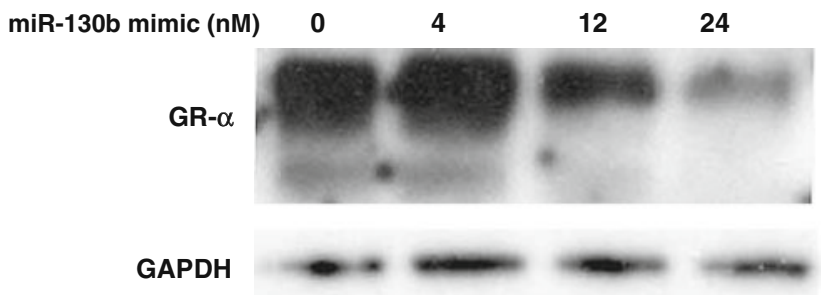

B.

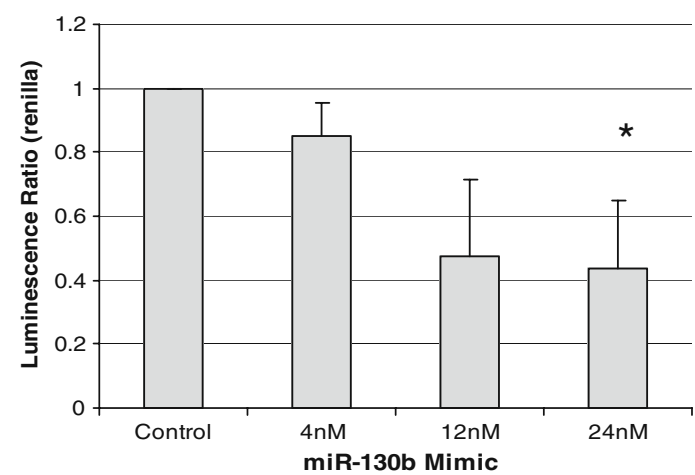

Fig. 3 MiR-130b decreases GR expression in MM.1S cells. a Immunoblot for GR- $\alpha$ using MM.1S cell lysates following transfection with increasing concentrations of miR-130b mimic. Equivalent protein is loaded in each lane as demonstrated by GAPDH signal. b Luciferase assay using GR 3'UTR construct cotransfected with increasing concentrations of miRNA-130b mimic normalized to signal from cells transfected with $24 \mathrm{nM}$ negative control miRNA $\left({ }^{*} p<0.05\right)$

cells with $100 \mathrm{nM}$ Dex to measure the impact of miR-130b on three aspects associated with GC-induced cell death. We analyzed the impact of miR-130b on the GC-induced expression of GILZ, or TSC22D3, which is a direct downstream target of GR [2]. GILZ is highly induced by GC treatment in MM1.S cells as previously described [2]. miR-130b significantly repressed the induction of GILZ compared to MM.1S cells transfected with scrambled control (Fig. 4b). To assess the impact of miR-130b on cell death, we performed flow cytometry staining for the apoptotic marker Annexin in addition to immunoblotting for cleavage of poly(ADP-ribose) polymerase (PARP), another marker of apoptosis. Compared to the cells transfected with negative control mimic, the cells transfected with miR-130b mimic experienced a reduction in glucocorticoid-induced apoptosis as measured by both Annexin staining (Fig. 4d) and a decrease in PARP cleavage (Fig. 4c).

We also tested inhibitors of miR-130b (antagomirs) in MM.1S, MM.1Re, and MM.1RL cells to determine if reducing endogenous expression of miR-130b has an effect on GR expression or GC sensitivity. With the expression of miR-130b knocked down below $10 \%$ of endogenous levels, no noticeable effect could be observed on measures of GR expression and GC sensitivity (Figs. S2, S3, and S4).

\section{Discussion}

Steroid hormone receptors are crucial regulators of disease and clinical intervention in several types of cancer. Many recent reports have highlighted miRNA interaction with steroid receptors in different malignancies, most notably estrogen receptor in breast cancer [24]. GR is a critical regulator of therapeutic response to GC treatment in MM. While there is existing precedence for miRNA regulation of GR in other tissues, this study represents the first observation in MM of the regulation of GR by miRNA,

miR-18 and miR-124 have been shown to reduce GR expression in the developing brain of rats [25-27]. Another group recently demonstrated that miR-128 and miR-221 are involved in glucocorticoid sensitivity in cells isolated from a spectrum of acute lymphocytic leukemia patients [28]. Profiling miRNA expression in MM patient samples identifies a number of miRNAs with differential expression when compared to normal controls [29-32]. The following set of miRNAs: miR-93, miR-25, miR-92, miR-19a, miR$19 \mathrm{~b}$, and miR-32, are significantly overexpressed, while miR-let7-b, miR-let7-i, miR-let7-c, miR-29a, and miR-29b are significantly downregulated in MM. Heterogeneous expression of miR-181a and miR-181b was observed in cell lines and in $50 \%$ of the patients [13]. Taken together, the importance of miRNA in $\mathrm{MM}$ and the evidence for regulation of GR by miRNAs in other systems, a role for miRNA in the regulation of GR in MM is likely.

The miRNA identified in this study, miR-130b, has not been studied in great detail. However, in all the reports, miR-130b appears to support cell survival. miR-130b has been postulated to regulate a p53-related protein (TP53INP1) in HTLV-transformed T cells, and miRNA$130 \mathrm{~b}$ can be transcriptionally regulated by the viral oncoprotein Tax in this system [33]. In gastric cancers, miR-130b was shown to regulate the tumor suppressor gene RUNX3 [34]. miR-130b was among a number of miRNAs shown to downregulate $\mathrm{p} 21$ (Waf1/Cip1), resulting in inhibition of cellular senescence $[35,36]$. Here, we show that miR-130b can also support cell survival by reducing sensitivity to GC-induced cell death through its target, GR.

While the average survival for MM has improved due to the application of new treatment options including combination therapies that involve using GCs with other therapeutics, the disease remains uniformly fatal. Elucidating the precise mechanism behind $\mathrm{GC}$ resistance in this disease could provide new opportunities for future therapeutic intervention. These findings indicate that in MM cells, miRNAs are likely to play an important role in the response to GCs and in the development of resistance to GCs. The evidence in this report suggests that miR-130b targets GR transcripts and further impacts GC responses. One possible interpretation of the data presented in Fig. 3 is 
A.

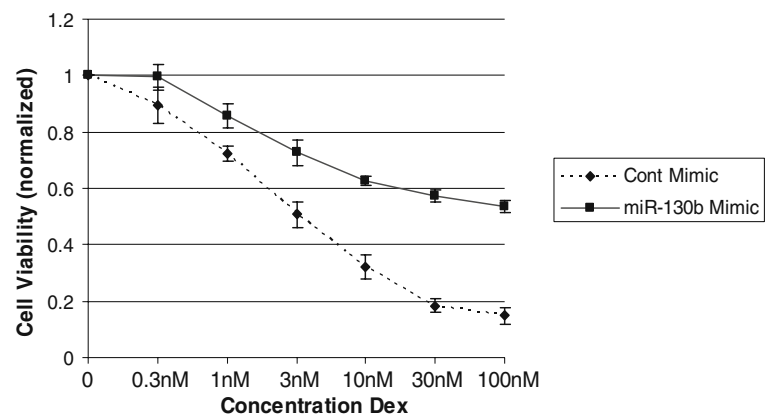

C.

\begin{tabular}{l|l|l|l|l|l|l}
$\operatorname{miR}-130 b$ \\
Mimic $(\mathrm{nM})$ & 0 & 1 & 10 & 0 & 1 & 10 \\
\hline 24hr 100nM Dex & - & - & - & + & + & +
\end{tabular}

PARP

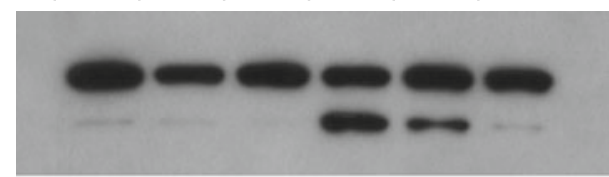

GAPDH

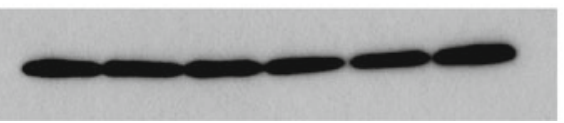

B.

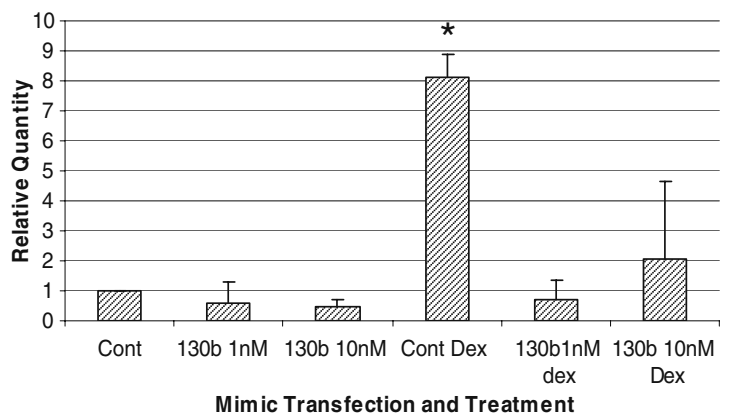

D.

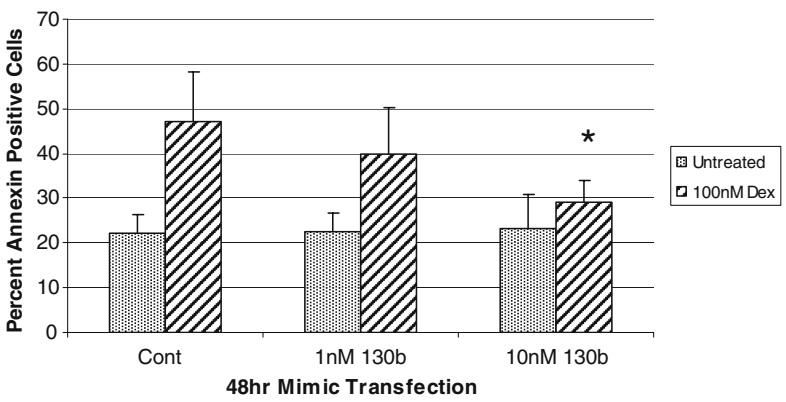

absence of $100 \mathrm{nM}$ dexamethasone normalized to untreated control. c Impact of miR-130b on the GC induction of apoptosis. Immunoblot of lysates from MM.1S cells transfected for $48 \mathrm{~h}$ as indicated with either10 $\mathrm{nM}$ control mimic (0) and 1 or $10 \mathrm{nM}$ miR-130b mimic. Cells were treated plus or minus $100 \mathrm{nM}$ dexamethasone for an additional $24 \mathrm{~h}$. Apoptosis was assessed based on PARP cleavage. d Annexin staining of MM.1S cells $72 \mathrm{~h}$ after transfection with either $10 \mathrm{nM}$ negative control mimic, $1 \mathrm{nM}$ miR-130b mimic, or $10 \mathrm{nM}$ miR-130b mimic and treated $+/-100 \mathrm{nM}$ Dex for $48 \mathrm{~h}$ (relative to MM.1S control $* p<0.05$ )

therefore do not appear to be coregulated with GR. NR3C2 is expressed at a reduced level in the MM.1RL cells, and we are therefore investigating whether this gene is an authentic target of miR-130b and if NR3C2 impacts GC responsiveness.

The lack of a measurable effect of the miR-130b antagomir in the MM.1R cells might be explained by a number of possibilities. For example, the $90 \%$ knockdown of miR-130b achieved by antagomir transfection might be insufficient to abrogate GR suppression due to the potency of the remaining $10 \%$ of endogenous miR-130b in the GCresistant cells or the possible cooperation of other miRNAs that have not been reduced. Additionally, miR-130b is most likely not the only factor contributing to GC resistance in this model system, but more likely is one of multiple factors which may include additional miRNAs and other regulatory elements within the cell that contribute to posttranscriptional gene regulation. However, the increased expression of miR-130b in MM.1R cells and the ability of miR-130b in GC-sensitive versus -resistant MM lines (Fig. S5) and 
mimics to reduce GR protein levels and GC sensitivity in MM.1S suggest that this miRNA may serve as a potential biomarker for identifying patients who are refractory to GCs.

Acknowledgments We would like to thank Pablo N. Quintana for the technical assistance on this project. This work was supported in whole or in part by NIH Grant R01CA 85919 (to S. R.).

Conflict of Interest Statement The authors declare that they have no conflict of interest.

\section{References}

1. Greenstein S, Ghias K, Krett NL, Rosen ST (2002) Mechanisms of glucocorticoid-mediated apoptosis in hematological malignancies. Clin Cancer Res 8:1681-1694

2. Grugan KD, Ma C, Singhal S, Krett NL, Rosen ST (2008) Dual regulation of glucocorticoid-induced leucine zipper (GILZ) by the glucocorticoid receptor and the PI3-kinase/AKT pathways in multiple myeloma. J Steroid Biochem Mol Biol 110:244-254

3. Moalli PA, Rosen ST (1994) Glucocorticoid receptors and resistance to glucocorticoids in hematologic malignancies. Leuk Lymphoma 15:363-374

4. Sanchez-Vega B, Gandhi V (2009) Glucocorticoid resistance in a multiple myeloma cell line is regulated by a transcription elongation block in the glucocorticoid receptor gene (NR3C1). Br J Haematol 144:856-864

5. Sharma S, Lichtenstein A (2008) Dexamethasone-induced apoptotic mechanisms in myeloma cells investigated by analysis of mutant glucocorticoid receptors. Blood 112:1338-1345

6. Geley S, Hartmann BL, Hala M, Strasser-Wozak EM, Kapelari K, Kofler R (1996) Resistance to glucocorticoid-induced apoptosis in human T-cell acute lymphoblastic leukemia CEM-C1 cells is due to insufficient glucocorticoid receptor expression. Cancer Res 56:5033-5038

7. Kino T, Stauber RH, Resau JH, Pavlakis GN, Chrousos GP (2001) Pathologic human GR mutant has a transdominant negative effect on the wild-type GR by inhibiting its translocation into the nucleus: importance of the ligand-binding domain for intracellular GR trafficking. J Clin Endocrinol Metab 86:5600-5608

8. Iacobelli S, Marchetti P, De Rossi G, Mandelli F, Gentiloni N (1987) Glucocorticoid receptors predict response to combination chemotherapy in patients with acute lymphoblastic leukemia. Oncology 44:13-16

9. Ma S, Zhan F, Ma C, Tessel M, Zhang L, Rajkumar S, Singhal S, Barlogie B, Shaughnessy J, Rosen ST, Krett NL (2008) Glucocorticoid receptor expression correlates with clinical outcome in myeloma patients treated with glucocorticoid-containing regimens. Blood 112:600, ASH Annual Meeting Abstracts, San Francisco, CA, 2008

10. Greenstein S, Krett NL, Kurosawa Y, Ma C, Chauhan D, Hideshima T, Anderson KC, Rosen ST (2003) Characterization of the MM.1 human multiple myeloma (MM) cell lines: a model system to elucidate the characteristics, behavior, and signaling of steroid-sensitive and -resistant MM cells. Exp Hematol 31:271282

11. Friedman RC, Farh KK, Burge CB, Bartel DP (2009) Most mammalian mRNAs are conserved targets of microRNAs. Genome Res 19:92-105

12. Lim LP, Lau NC, Garrett-Engele P, Grimson A, Schelter JM, Castle J, Bartel DP, Linsley PS, Johnson JM (2005) Microarray analysis shows that some microRNAs downregulate large numbers of target mRNAs. Nature 433:769-773
13. Pichiorri F, Suh SS, Ladetto M, Kuehl M, Palumbo T, Drandi D, Taccioli C, Zanesi N, Alder H, Hagan JP, Munker R, Volinia S, Boccadoro M, Garzon R, Palumbo A, Aqeilan RI, Croce CM (2008) MicroRNAs regulate critical genes associated with multiple myeloma pathogenesis. Proc Natl Acad Sci USA 105:12885-12890

14. Corthals SL, Jongen-Lavrencic M, de Knegt Y, Peeters JK, Beverloo HB, Lokhorst HM, Sonneveld P (2010) Micro-RNA15a and micro-RNA-16 expression and chromosome 13 deletions in multiple myeloma. Leuk Res 34:677-681

15. Iorio MV, Croce CM (2009) MicroRNAs in cancer: small molecules with a huge impact. J Clin Oncol 27:5848-5856

16. Maziere P, Enright AJ (2007) Prediction of microRNA targets. Drug Discov Today 12:452-458

17. Hollenberg SM, Weinberger C, Ong ES, Cerelli G, Oro A, Lebo R, Thompson EB, Rosenfeld MG, Evans RM (1985) Primary structure and expression of a functional human glucocorticoid receptor cDNA. Nature 318:635-641

18. Kolachala VL, Wang L, Obertone TS, Prasad M, Yan Y, Dalmasso G, Gewirtz A, Merlin D, Sitaraman SV (2010) Adenosine 2B receptor expression is post-transcriptionally regulated by microRNA. J Biol Chem 285:18184-18189

19. Querfeld C, Rizvi MA, Kuzel TM, Guitart J, Rademaker A, Sabharwal SS, Krett NL, Rosen ST (2006) The selective protein kinase $\mathrm{C}$ beta inhibitor enzastaurin induces apoptosis in cutaneous T-cell lymphoma cell lines through the AKT pathway. J Invest Dermatol 126:1641-1647

20. Rizvi MA, Ghias K, Davies KM, Ma C, Weinberg F, Munshi HG, Krett NL, Rosen ST (2006) Enzastaurin (LY317615), a protein kinase Cbeta inhibitor, inhibits the AKT pathway and induces apoptosis in multiple myeloma cell lines. Mol Cancer Ther 5:1783-1789

21. Moalli PA, Pillay S, Weiner D, Leikin R, Rosen ST (1992) A mechanism of resistance to glucocorticoids in multiple myeloma: transient expression of a truncated glucocorticoid receptor mRNA. Blood 79:213-222

22. Creighton CJ, Reid JG, Gunaratne PH (2009) Expression profiling of microRNAs by deep sequencing. Brief Bioinform 10:490-497

23. Lewis BP, Burge CB, Bartel DP (2005) Conserved seed pairing, often flanked by adenosines, indicates that thousands of human genes are microRNA targets. Cell 120:15-20

24. Tessel MA, Krett NL, Rosen ST (2010) Steroid receptor and microRNA regulation in cancer. Curr Opin Oncol 22:592-597

25. de Kloet ER, Fitzsimons CP, Datson NA, Meijer OC, Vreugdenhil E (2009) Glucocorticoid signaling and stress-related limbic susceptibility pathway: about receptors, transcription machinery and microRNA. Brain Res 1293:129-141

26. Uchida S, Nishida A, Hara $K$, Kamemoto T, Suetsugi $M$, Fujimoto M, Watanuki T, Wakabayashi Y, Otsuki K, McEwen BS, Watanabe Y (2008) Characterization of the vulnerability to repeated stress in Fischer 344 rats: possible involvement of microRNA-mediated down-regulation of the glucocorticoid receptor. Eur J Neurosci 27:2250-2261

27. Vreugdenhil E, Verissimo CS, Mariman R, Kamphorst JT, Barbosa JS, Zweers T, Champagne DL, Schouten T, Meijer OC, de Kloet ER, Fitzsimons CP (2009) MicroRNA 18 and 124a down-regulate the glucocorticoid receptor: implications for glucocorticoid responsiveness in the brain. Endocrinology 150:2220 2228

28. Kotani A, Ha D, Hsieh J, Rao PK, Schotte D, den Boer ML, Armstrong SA, Lodish HF (2009) miR-128b is a potent glucocorticoid sensitizer in MLL-AF4 acute lymphocytic leukemia cells and exerts cooperative effects with miR-221. Blood 114:4169-4178

29. Lionetti M, Biasiolo M, Agnelli L, Todoerti K, Mosca L, Fabris S, Sales G, Deliliers GL, Bicciato S, Lombardi L, 
Bortoluzzi S, Neri A (2009) Identification of microRNA expression patterns and definition of a microRNA/mRNA regulatory network in distinct molecular groups of multiple myeloma. Blood 114:e20-26

30. Roccaro AM, Sacco A, Thompson B, Leleu X, Azab AK, Azab F, Runnels J, Jia X, Ngo HT, Melhem MR, Lin CP, Ribatti D, Rollins BJ, Witzig TE, Anderson KC, Ghobrial IM (2009) MicroRNAs $15 \mathrm{a}$ and 16 regulate tumor proliferation in multiple myeloma. Blood 113:6669-6680

31. Ronchetti D, Lionetti M, Mosca L, Agnelli L, Andronache A, Fabris S, Deliliers GL, Neri A (2008) An integrative genomic approach reveals coordinated expression of intronic miR-335, miR-342, and miR-561 with deregulated host genes in multiple myeloma. BMC Med Genomics 1:37

32. Unno K, Zhou Y, Zimmerman T, Platanias LC, Wickrema A (2009) Identification of a novel microRNA cluster miR-193b-365 in multiple myeloma. Leuk Lymphoma 50:1865-1871
33. Yeung ML, Yasunaga J, Bennasser Y, Dusetti N, Harris D, Ahmad N, Matsuoka M, Jeang KT (2008) Roles for microRNAs, miR-93 and miR-130b, and tumor protein 53-induced nuclear protein 1 tumor suppressor in cell growth dysregulation by human T-cell lymphotrophic virus 1. Cancer Res 68:8976-8985

34. Lai KW, Koh KX, Loh M, Tada K, Subramaniam MM, Lim XY, Vaithilingam A, Salto-Tellez M, Iacopetta B, Ito Y, Soong R (2010) MicroRNA-130b regulates the tumour suppressor RUNX3 in gastric cancer. Eur J Cancer 46:1456-1463

35. Borgdorff V, Lleonart ME, Bishop CL, Fessart D, Bergin AH, Overhoff MG, Beach DH (2010) Multiple microRNAs rescue from Ras-induced senescence by inhibiting p21(Waf1/Cip1). Oncogene 29:2262-2271

36. Malzkorn B, Wolter M, Liesenberg F, Grzendowski M, Stuhler K, Meyer HE, Reifenberger G (2010) Identification and functional characterization of microRNAs involved in the malignant progression of gliomas. Brain Pathol 20:539-550 